\title{
Analysis of Energy Consumption for Biomass Drying Process
}

\author{
Edgars Vigants, Girts Vigants, Ivars Veidenbergs, Dace Lauka, Krista Klavina, \\ Dagnija Blumberga \\ Riga Technical University, Institute Of Energy Systems and Environment. \\ Azenes iela 12/1, Riga, LV-1048, Latvia
}

\begin{abstract}
This study is dedicated to the analysis of the drying process energy consumption. In order to evaluate the main energetic processes that consume the most energy, the energy consumption of each individual drying process with and without air recirculation was modelled. The model shows that drying agent (air) recirculation is not an energy-saving operation, since it increases the total electricity and heat consumption. Recirculation of the drying agent increases the moisture content of the drying agent at the dryer entrance, which increases the need for fresh air in the dryer so that it can absorb the evaporating moisture from the dried material. An increased flow of the drying agent in the dryer increases the heat and electricity consumption.
\end{abstract}

Keywords: biomass, dryer, energy consumption, moisture content.

\section{INTRODUCTION}

Biomass drying is an energy-intensive process that consumes heat energy and electric energy. The principles and parameters of the drying process operations that influence a dryer's energy use are listed below [1]:

1. Type of heat supply, or heat transfer, in the dryer. Heat is transferred in the surrounding environment via thermal conduction, convection or radiation, and these principles are exploited in the dryer. Specific dryer variations include the use of an electrical field, microwaves, solar energy and freeze drying;

2. Temperature and pressure of the drying environment, which, in turn, influences the drying time;

3. The movement of materials around in the dryer is a key factor in drying materials of a certain size;

4. The type of drying operation, which can be continual or periodical (batch-type), which, in turn, influences the productivity of the dryer and its energy consumption;

5. The efficiency of the drying process is also influence by the direction of flow for the drying agent and the dried material.

The above-listed factors are the technological parameters for various dryers, but the most important factor is to evaluate the characteristics of the particular material to be dried and thereby choose the most appropriate drying method and dryer type. The dryer's basic goal is to supply heat to the materials that need to be dried in order to evaporate the moisture in those materials. There are three types of dryer:
- Convection-type dryers. The evaporation of the moisture content in the material by applying heat from the surrounding atmosphere or the covering the material with a drying agent is called convection drying. Convection drying is the most popular method used when drying fine material such as wood chips. During convection drying, the most common drying agent is heated outdoor air; other agents include flue gases and superheated steam or other inert gases (N2) that ensure evaporation. The drying agent absorbs the evaporated moisture, which is then usually released in the atmosphere. Convection-type dryers operate at atmospheric pressure, and they can operate in a very broad range of temperatures $\left(80-600{ }^{\circ} \mathrm{C}\right)$. Dryers using convection heat transfer are called direct dryers. Belt, tunnel, rotation, pneumatic, spray and also fluidised-bed dryers use convection heat transfer. Drying times in such dryers are very variable. Pneumatic dryers and spray-type dryers have drying times of less than one minute, while drying in belt, tunnel and rotation dryers can take more than an hour [2].

- Indirect dryers. Dryers in which the dried material receives the necessary heat by coming into contact with a hot surface, which is heated by a drying agent, are called indirect dryers. In such dryers, superheated steam or high-temperature flue gases are used as the drying agent to heat the surface. Heat is supplied in a heat supply method, and such dryers are used to dry very moist material as well as heatresistant material. Often, the drying process can be performed in a vacuum. Contact drying can be used as a pre-drying method for a convection-type dryer in

ISSN 1691-5402 
order to ensure an even drying process, or both processes can be combined to ensure more effective drying; for example, the pipes through which the hot drying agent flows can be placed in a rotation or fluidised-bed dryer that uses convection drying, thereby lowering energy consumption. The contact drying process is used in drum, pipe rotation and fluidised-bed as well as spray dryers [3].

- Radiation dryers. Heat supply to a dryer can also be accomplished through the radiation process. In radiation dryers, more heat is transferred to the material than convection or contact dryers. They are used to dry materials that are difficult to dry in order to noticeably lessen the drying time, because infra-red radiation enters the material deeper, thereby ensuring better evaporation of moisture from the inner layers of the material. Such a drying method requires a heat source, such as natural gas or flue gases that heat the surface (a metal or ceramic screen) that generates the infra-red radiation [4]. Radiation heat transfer can be performed in a belt dryer, in which a screen generating infra-red radiation is located above the moving belt.

When drying a specific type of material, it is important to evaluate the suitability of the dryer to the material and the movement of the material during the drying process, because this influences the total energy consumption of the drying process. Smallsized materials (sawdust or wood chips) are appropriate for rotation, tunnel, belt, fluidised-bed and pneumatic dryers. In such dryers (except rotation dryers, where the material is moved by gravitation), supplemental energy is required to move the material during the drying process. The electricity consumption needed to move belts or trolleys, as well as the blowing of air, depends on the volume of dried material, or flow. Of the above-mentioned methods, belt dryers consume the smallest amount of electricity [1].

In evaluating the characteristics of the dried material and the dryer's technological parameters, it is concluded that the most appropriate dryer for the drying of sawdust is a continuous convection dryer, which results in the lowest operational costs. Belt and rotation dryers, as well as pneumatic dryers, are the most commonly dryers used for sawdust [5].

Drying is a process that consumes considerable amounts of energy and for which it would be very important to implement energy-saving measures, thereby reducing energy consumption during the drying process. This paper focusses on energy consumption during a single drying cycle and over the course of a year. It therefore provides a description of a model of the drying process with and without drying agent recirculation over the course of a year.

\section{MODEL OF THE DRYING PROCESS}

A simplified mass and energy flow of the model are shown in the diagram in Figure 1. The diagram shows all the elements of the process needed to successfully model the drying process.

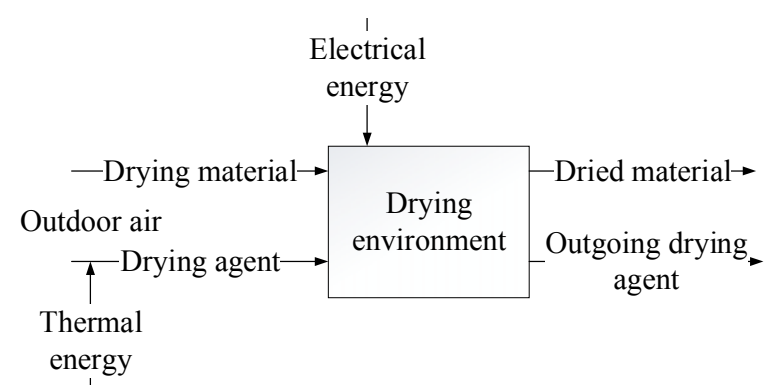

Fig. 1. Simplified mass and energy flow of the model

Figure 1 shows all the elements that are necessary to successfully simulate the drying process.

Outdoor air is heated in heat exchangers. The heat exchangers are powered by the outgoing heat of the heat carrier from the cogeneration unit, which is at the temperature of $90{ }^{\circ} \mathrm{C}$. The outdoor air is drawn into the dryer with fans. By creating a perpendicular flow of air, heat is added to the outdoor air, and the air heats up, thereby becoming a drying agent. The drying agent is heated to $80{ }^{\circ} \mathrm{C}$, thereby cooling the cogeneration heat carrier to $50{ }^{\circ} \mathrm{C}$. The drying agent enters the drying chamber, or drying environment, in which the moveable belt is located. The dried material is spread out to a specific depth on the belt. The relative moisture content of the input material may vary, but the moisture content of the outgoing material is $25 \%$, which is a constant parameter value. The fact that the outgoing moisture content of the material is defined in turn influences other drying parameters, such as drying time and the volume of supplied energy.

The main drying process parameter values - drying time and the required amount of heat - are obtained by the dryer calculations. To simplify, the drying process is the supply of heat to the material in order to obtain good-quality, dry material in as short time as much as possible, which can then be sold on the market for a profit. Thus, one of the most important parameters characterising the drying process is the drying time. The second most important parameter is the amount of heat needed to successfully implement the drying process, which in turn directly influences the drying costs.

The first calculation parameter characterising the drying environment is the equilibrium moisture content of the material (wood). The equilibrium moisture content of wood is the moisture level towards which the drying wood naturally tends while standing in a constant drying environment (at the temperature and moisture content of the drying agent). This means that at this point the material no longer gains nor loses moisture; it is in equilibrium with the surrounding environment and parameters. As the drying environment's parameters change, the 
equilibrium moisture content also changes. This means that if damp wood is placed in an environment with high temperature and low moisture content, the moisture content of the wood will gradually decrease as the result of desorption. However, if dry wood is placed in an environment where the air is highly saturated, the wood will gain moisture by way of adsorption. By standing in an environment with constant parameters for an extended amount of time, the moisture content of the wood also becomes constant; in other words, it reaches the equilibrium moisture content value. The equilibrium moisture content of wood increases as the relative moisture of the environment increases and the temperature of the drying environment decreases [6].

Equilibrium moisture content is usually not reached when drying wood, but it would be possible to reach it by noticeably increasing the drying time. At the end of the drying process, the outgoing moisture content of the dried material falls between the boundaries of equilibrium moisture content and outgoing moisture content. In any case, it is impossible to reach the material's equilibrium moisture content by drying it at a high temperature and low relative moisture - and this is also not desirable - because as soon as the dried material would be taken out of the drying chamber, it would begin to absorb moisture from the outdoor environment by means of adsorption, because the relative moisture content would increase and the temperature would decrease, and the material's equilibrium moisture content value would increase [3].

It is important to calculate the equilibrium moisture content of wood in the model of the drying process, because it influences the drying time at specific drying environment parameters such as temperature and relative moisture. The equilibrium moisture content of wood can be determined by diagrams, but for simplicity's sake it will be calculated here using the formulas listed below.

To calculate the equilibrium moisture content of wood at constant drying environment parameters $\left(X_{e}\right)$ [6], Formula 1 needs to be used:

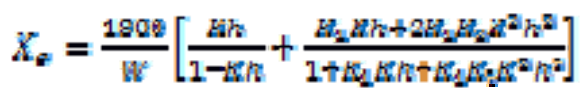

where

$\mathrm{k}, \mathrm{k}_{1}, \mathrm{k}_{2}$ - empirical coefficients;

$\mathrm{h}$ - parameter;

$\mathrm{W}$ - drying rate, tonne/h.

The following formulas (in which $T=$ drying environment temperature, ${ }^{\circ} \mathrm{C}$ ) are used to calculate the parameters included in the formula that describe the adsorption processes in wood:

$W=349+1.29 T+0.0135 T^{2}$

$$
\begin{aligned}
& K=0.805+0.000736 T-0.00000273 T^{2} \\
& K_{1}=6.27-0.00938 T-0.000303 T^{2} \\
& K_{2}=1.91+0.0407 T-0.000293 T^{2}
\end{aligned}
$$

The relative moisture of the drying environment, which is in turn dependant on the moisture content of the outdoor air, is used to obtain the parameter:

$h=\frac{\varphi}{100}$

where

$\varphi$ - relative humidity, $\%$.

In order to calculate the drying time, it is important to understand what the drying material is like and what are its characterising parameters. The drying time constant expresses the features of the specific material to be dried, which in turn influences the total drying time.

The drying time constant is influenced by the temperature of the drying environment and the size and density of the material. In general, the drying time constant is influenced by the species of wood. Denser woods, such as oak, require a longer drying time. As mentioned above, sawdust and wood chip density is influenced by their relative moisture content, which is in turn influenced by various parameters: weather conditions, time of year, amount of precipitation. The following formula is used to calculate the drying time constant $\left(t_{c}\right)[7,8]$ :

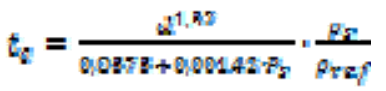

where

$\rho_{\text {ref }}$ - wood density, $\mathrm{kg} / \mathrm{m}^{3}$;

$\mathrm{d}$ - particle size, $\mathrm{m}$;

$\mathrm{P}_{\mathrm{s}}$ - vapour pressure at drying conditions, bar.

The partial pressure of the water vapour of the drying environment, which depends on the moisture content of the outdoor air, is also an influencing factor in the drying process. It can thereby be stated that the outdoor air parameters, such as temperature and moisture content, are influencing factors in the length of the drying process. The drying time $(t)$ is calculated thus [9]:

$t=-t_{q}\left[n\left[\frac{\left[X-x_{R}\right]}{\left[x_{\mathrm{g}}-x_{\mathrm{g}}\right]}\right]\right.$

where

$\mathrm{X}$ - final moisture content, $\mathrm{kg} / \mathrm{kg}$ dry basis;

$\mathrm{X}_{\mathrm{o}}$ - initial moisture content, $\mathrm{kg} / \mathrm{kg}$ dry basis;

$\mathrm{X}_{\mathrm{e}}-$ equilibrium moisture content, $\mathrm{kg} / \mathrm{kg}$ dry basis.

In order to calculate the amount of heat and electricity needed to ensure the drying process, it is important to determine the flow of outdoor air 
necessary to reach a specific moisture content for the outgoing material. As mentioned above, the drying agent (or, heated outdoor air) absorbs the evaporated moisture from the material. In order to determine the amount of fresh air needed to absorb the evaporated moisture from the material, it must be determined what amount of moisture must be evaporated from the material in order to reach the indicated outgoing moisture content. The amount of moisture to be evaporated from the material $(W)$ is calculated thus [9]:

$$
F=F\left(w_{e}-X^{2}\right)
$$

where

$\mathrm{F}$ - feed flow rate, tonne/h.

So, the flow of evaporated moisture in the material is determined by the flow and moisture content of the material before and after drying. Actually, the formula is the moisture mass balance of the material in the dryer. As the moisture content of the material decreases before drying, the evaporated moisture mass would also decrease, which would in turn shorten the drying time and amount of energy consumed.

In order for the drying process to take place, the drying agent must absorb the moisture evaporated by the material and remove it from the drying chamber. The following formula is used to determine the amount of air needed for it to be able to absorb the moisture evaporated from the dried material $\left(F_{a}\right)[45]$ :

$$
F_{Q}=\frac{w}{\left(y-y_{g}\right)}
$$

where

$\mathrm{Y}$ - drying air humidity, $\mathrm{kg} / \mathrm{kg}$ dry basis;

$\mathrm{Y}_{\mathrm{o}}$ - ambient air humidity, $\mathrm{kg} / \mathrm{kg}$ dry basis.

The amount of outdoor air to be heated is influenced by the air temperature and moisture content as well as the moisture content of the material before drying. The amount of drying agent in the dryer influences the total energy consumption needed to operate the suction fans as well as the heat consumption needed to heat the specific amount of air. This means that there is a direct correlation between the moisture content of the outdoor air and the amount of drying agent in the dryer. The moisture content of the outdoor air is thereby one of the most important parameters influencing the energy consumption of the drying process.

The formulas listed below are used to calculate the heat consumption needed to ensure an effective drying process. Heat is needed for the drying process in order to promote the evaporation of moisture and to heat the material and outdoor air. The total heat consumption is obtained by adding up all of the above-mentioned heat consumers.

The amount of heat needed to evaporate the moisture from the material is $\left(Q_{m}\right)$ calculated thus [9]:

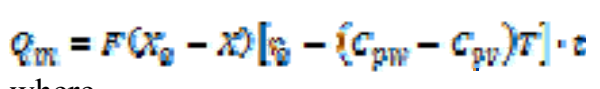

where

$\mathrm{r}_{\mathrm{o}}$ - latent heat, $\mathrm{kJ} / \mathrm{kg}$;

$\mathrm{C}_{\mathrm{pw}}$ - specific heat of water, $\mathrm{kJ} / \mathrm{kg} \mathrm{K}$;

$\mathrm{C}_{\mathrm{pv}}$ - specific heat of water vapor, $\mathrm{kJ} / \mathrm{kg} \mathrm{K}$.

The amount of heat needed to evaporate the moisture from the material is dependent on the moisture content of the material before drying and the temperature of the drying agent as well as the length of the drying process.

The heat consumption needed to heat wood chips (dried material) $\left(Q_{d w}\right)$ is calculated thus:

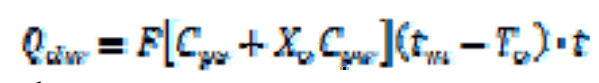

where

$\mathrm{C}_{\mathrm{ps}}-$ specific heat of dry material, $\mathrm{kJ} / \mathrm{kg} \mathrm{K}$;

$\mathrm{t}_{\mathrm{m}}$ - drying air temperature, ${ }^{\circ} \mathrm{C}$;

$\mathrm{T}_{\mathrm{o}}$ - ambient temperature, ${ }^{\circ} \mathrm{C}$.

The amount of heat needed to heat wood chips depends on the moisture content of the material before drying, the outdoor air temperature and the drying agent's wet-bulb temperature as well as the length of the drying process. The temperature of the dried wood chips is equal to the drying agent's wet-bulb temperature, which in turn depends on the heat content of the drying agent, which is calculated using the moisture content of the outdoor air. As the temperature of the outdoor air increases, its moisture content increases as well, which in turn increases the drying agent's wet-bulb temperature. Therefore, in the summer, when the outdoor air temperature is higher, the amount of heat needed to heat the wood chips will be lower.

The heat consumption needed to heat the air $\left(\mathrm{Q}_{\mathrm{a}}\right)$ is calculated thus [9]:

$$
Q_{a}=F_{a}\left[C_{p a}+Y_{e} C_{p w}\right]\left(T-T_{e}\right)-t
$$

where

$\mathrm{C}_{\mathrm{pa}}$ - specific heat of air, $\mathrm{kJ} / \mathrm{kg} \mathrm{K}$.

The amount of heat needed to heat the air depends on the temperature and moisture content of the outdoor air as well as the length of the drying process. Over the course of a year, the heat consumption needed to heat the air will decrease, because the temperature of the outdoor air will be higher, so the difference between the outdoor air and the temperature to which the drying agent needs to be heated will be smaller and less heat will have to be supplied to the air to reach the appropriate drying environment temperature.

The following formula is used to calculate the total amount of heat needed $\left(Q_{t o t}\right)$ : 


$$
Q_{t o r}=Q_{m}+Q_{d W}+Q_{a}
$$

The following correlation is used to evaluate the efficiency of the dryer's operations $\left(n_{q}\right)$ [9]:

$$
n_{q}=\frac{Q_{m}}{Q_{\operatorname{tat}}}
$$

The main task of the drying process is to evaporate moisture from the material, and it is therefore important to evaluate how much of the supplied heat is used for its intended purpose, which in turn shows how efficient the system's operations are in ensuring the drying process. This parameter depends on the moisture content of the material before drying. In addition, if the total amount of heat consumed is noticeably larger than the heat needed to evaporate the moisture, this could indicate excessive heat loss or less-than-optimal operation of the dryer.

\section{RESULTS}

In order to evaluate the main energetic process that consumes more energy, the energy consumption needs of each separate drying process were calculated. A detailed description of the heat and electricity consumption ( $\mathrm{y}-$ axis, in $\mathrm{kWh})$ is shown in the graphs in Figure 2.

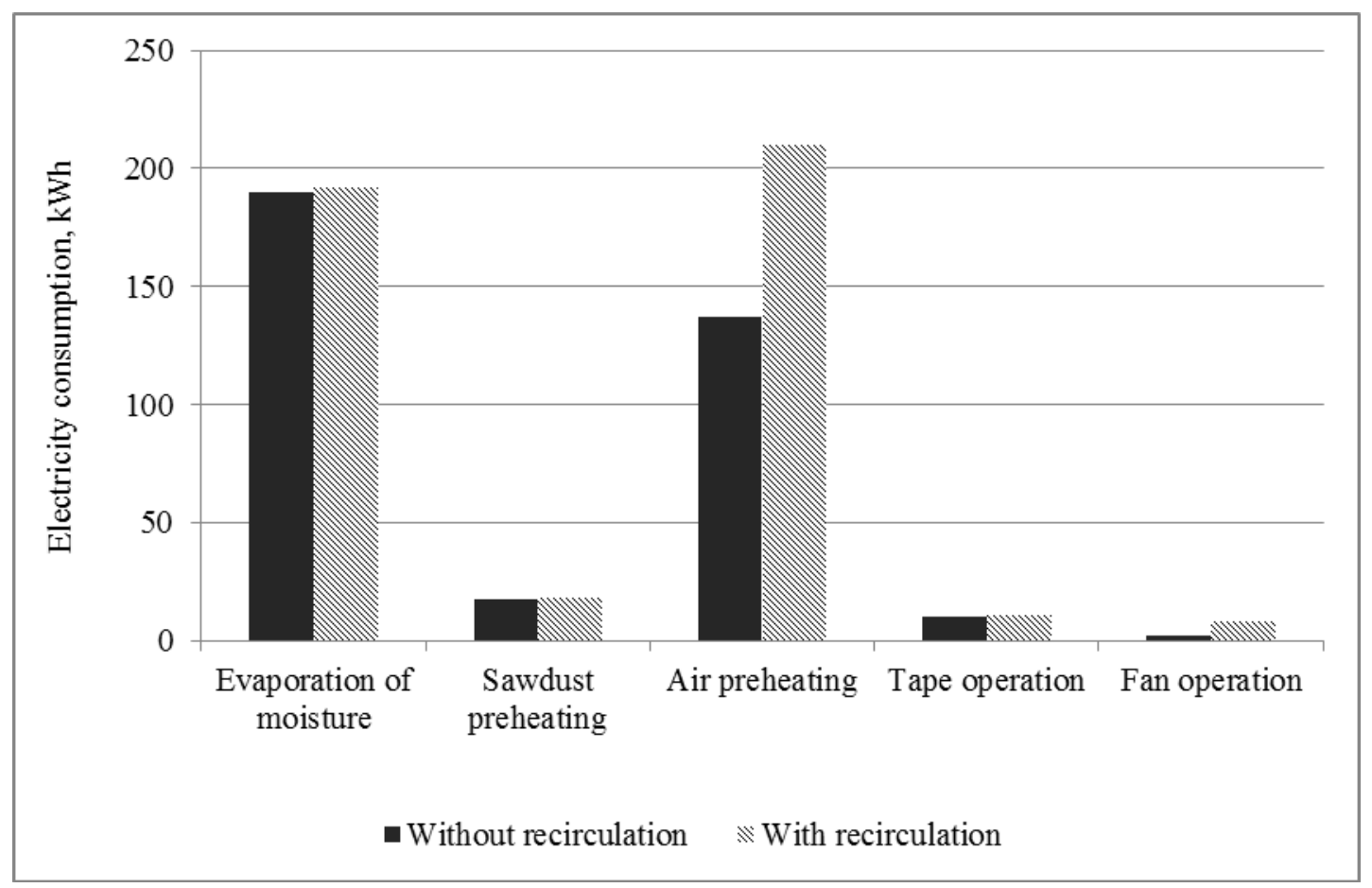

Fig. 2. Energy consumption with and without recirculation of the drying agent

As seen in Figure 2, when compared with drying without air recirculation, the greatest increase in heat consumption is for the heating of the air. This can be explained by the fact that during the drying process with air recirculation the moisture content of the outgoing drying agent increases, which in turn increases the amount of fresh air needed in the dryer to absorb the evaporated moisture from the material to be dried. If the recirculation of the drying agent is increased by $50 \%$, the amount of heat needed to heat the air increases by $53 \%$. As the flow of air needed to ensure the drying process with air recirculation increases, the amount of outgoing drying agent increases, which in turn substantially increases the amount of electricity needed to operate the fan. In a drying process with $50 \%$ air recirculation, the amount of electricity needed to move the drying agent is approximately 2.5 times greater than it is for drying an equal amount of material using a drying process without air recirculation.

\section{CONCLUSIONS}

1. Recirculation of a drying agent (air) does not minimise energy use, because it increases the total consumption of electricity and heat.

2. Recirculation of a drying agent influences an increase in the moisture content of the drying agent at the dryer's entry point, which increases the need for fresh air in the dryer so that it can absorb the evaporated moisture from the dried material. An increased drying agent flow in the dryer increases the consumption of heat and electricity. 


\section{ACKNOWLEDGEMENT}

This work was supported by the project "Development of Innovative Biomass Gasification Technology for Syngas Production" (the European Economic Area (EEA) Financial Mechanism 20092014 Programme's "National Climate Policy" open call "Emission reduction technologies including renewable energy, sustainable buildings and technology development".)

\section{REFERENCES}

[1] Mujumdar A.S. Principles, classification, and selection of dryers. Handbook of Industrial Drying. - London: Taylor and Francis Group, 2006. - 1282 p.

[2] Chen D., Zheng Y., Zhu X. Determination of effective moisture diffusivity and drying kinetics for poplar sawdust by thermogravimetric analysis under isothermal condition // Bioresource Technology. - No. 107 (2012) pp. 451 - 455.
[3] George D. Basic wood properties. Forest products measurements and conversion factors. - Washington: University of Washington, College of Forest Resources, 1994. $-12 \mathrm{p}$.

[4] George D. Chips, sawdust, planer shavings, bark and hog fuel. Forest products measurements and conversion factors. Washington: University of Washington, College of Forest Resources, 1994. - 15 p.

[5] Fagernas L., Brammer J., Wilen C., Lauer M., Verhoeff F. Drying of biomass for second generation synfuel production // Biomass and Bioenergy. - No. 34 (2010) pp. 1267 - 1277.

[6] Simpson T.W Equilibrium Moisture Content of Wood in Outdoor Locations in the United States and Worldwide. Madison: U.S. Department of Agriculture, Forest Service, Forest Products Laboratory, 2008. - $11 \mathrm{p}$

[7] Simpson W., Tschernitz J. Importance of thickness variation in kiln drying red oak lumber. - Madison: U.S. Department of Agriculture, Forest Service, Forest Products Laboratory, 2001. $-9 \mathrm{p}$.

[8] Wood density table // http://www.aqua-calc.com/page/densitytable // [15.05.2012.]

[9] Marouslis Z.B., Mujumdar S.A., Saravacos G.D. Spreadsheetaided dryer design. Handbook of Industrial Drying. - London: Taylor and Francis Group, 2006. - 1282 p. 